\title{
A Novel Method of a High Pressure Processing Pre-Treatment on the Juice Yield and Quality of Persimmon
}

\author{
Jiayue Xu ${ }^{1,+}$, Yilun Wang ${ }^{1,+}$, Xinyue Zhang ${ }^{1}$, Zhen Zhao ${ }^{1}$, Yao Yang ${ }^{1}$, Xin Yang ${ }^{1}$, Yongtao Wang ${ }^{1}$, Xiaojun Liao ${ }^{1}$ \\ and Liang Zhao ${ }^{1,2, *}$
}

Citation: $\mathrm{Xu}$, J.; Wang, Y.; Zhang, X.; Zhao, Z.; Yang, Y.; Yang, X.; Wang, Y.; Liao, X.; Zhao, L. A Novel Method of a High Pressure Processing Pre-Treatment on the Juice Yield and Quality of Persimmon. Foods 2021, 10 3069. https://doi.org/10.3390/ foods10123069

Academic Editor: Yong Yu

Received: 9 November 2021

Accepted: 3 December 2021

Published: 10 December 2021

Publisher's Note: MDPI stays neutral with regard to jurisdictional claims in published maps and institutional affiliations.

Copyright: (C) 2021 by the authors Licensee MDPI, Basel, Switzerland. This article is an open access article distributed under the terms and conditions of the Creative Commons Attribution (CC BY) license (https:// creativecommons.org/licenses/by/ $4.0 /)$.
1 National Engineering Research Center for Fruit and Vegetable Processing, Key Laboratory of Fruit and Vegetable Processing, Key Laboratory of Food Non-Thermal Processing, Ministry of Agricultural and Rural Affairs, College of Food Science \& Nutritional Engineering, China Agricultural University, Beijing 100083, China; xujiayue@cau.edu.cn (J.X.); wangyilun@yili.com (Y.W.); zhangxinyuezy@163.com (X.Z.); yousafzai823@163.com (Z.Z.); yy1221yhy@163.com (Y.Y.); 2018306100512@cau.edu.cn (X.Y.); wangyongtao102@163.com (Y.W.); liaoxjun@cau.edu.cn (X.L.)

2 Xinghua Industrial Research Centre for Food Science and Human Health, China Agricultural University, Xinghua 225700, China

* Correspondence: zhaoliang1987@cau.edu.cn; Tel.: +86-1062737464

+ Both (These) authors contributed equally to this work.

\begin{abstract}
This study investigates the effects of a high pressure processing pre-treatment (pre-HPP) on the juice yield of persimmon (Diospyros kaki L.) pulp and the pre-HPP plus HPP or thermal processing (TP) on microorganism inactivation and quality changes of the persimmon juice. The "Gongcheng" persimmon was selected with the highest juice yield (48.9\%), and the pre-HPP set at $300 \mathrm{MPa} / 8 \mathrm{~min}$ increased the juice yield by $60 \%$ through an increasing pectin methylesterase (PME) activity of $25.03 \%$ and by maintaining polygalacturonase (PG) activity. For different processing modes, namely, pre-HPP plus HPP at $550 \mathrm{Mpa} / 5 \mathrm{~min}$ and pre-HPP plus TP treatment at $95{ }^{\circ} \mathrm{C} / 5 \mathrm{~min}$, both of the guaranteed microorganisms in the juice were below $2.0 \mathrm{lg} \mathrm{CFU} / \mathrm{mL}$; however, the persimmon juice treated by the pre-HPP plus HPP had higher contents of total phenol and ascorbic acid which were $16.07 \mathrm{mg}$ GAE/100 $\mathrm{g}$ and $17.92 \mathrm{mg} / 100 \mathrm{~mL}$, respectively, a lower content of soluble tannin which was $55.64 \mu \mathrm{g} / \mathrm{mL}$, better clarity which was $18.6 \%$ and less color change where the $\Delta E$ was only 2.68 .
\end{abstract}

Keywords: persimmon; juice yield; high pressure processing; pectin methylesterase; enzyme activation; quality enhanced

\section{Introduction}

Persimmon (Diospyros kaki L.) is one of the most popular fruits in China. In 2017, China's persimmon yield was 3.25 million tons, accounting for $76 \%$ of the world's yield [1]. Although the harvest time of persimmon is short and it is a difficult fruit to transport, only one-tenth of those were able to be processed into dried persimmons and other products. Since the large amounts of tannin, pectin and protein in persimmon would affect the quality and the juice yield, persimmon juice products have rarely existed in the market.

A large amount of pectin could cause a low juice yield which is one of the main problems of persimmon juice processing. A traditional way to solve this problem is by adding an exogenous pectinase, such as PME and PG, which could increase the fruit juice yield, clarify the juice and increase membrane flux during ultrafiltration. In previous research, pectinase was added in the processing of juice with enzymatic hydrolysis at the appropriate time and temperature [2]; however, the main disadvantages of adding exogenous pectinase are its hidden safety perils and a complexity in formulating the optimum enzyme mixture, that also has a bad effect on the taste of the juice [3].

High pressure processing (HPP) is widely used in the food industry as a non-thermal technology, especially in fruits or vegetable products. Studies have indicated that compared to traditional thermal processing (TP), HPP efficiently enhances the microbial inactivation 
and enzyme denaturation with less damage on the low molecular weight compounds, like vitamins and flavoring agents [4]. However, some enzymes in food are pressure resistant and are even activated after HPP [5]. Several mechanisms were proposed for the pressure-induced activation of enzyme-catalyzed reactions: (1) changes in the structure of the enzyme; (2) accelerating the reaction rate of the enzyme; and (3) changes in the substrate or solvent's physical properties (such as $\mathrm{pH}$, density, viscosity and so forth) that affect the enzyme structure or the rate-limiting step [5]. In tomato juice, the PME activity was 1.62 times that of the control as was found under $600 \mathrm{Mpa} / 20^{\circ} \mathrm{C} / 10 \mathrm{~min}$ [6].

Recently some studies have investigated persimmon treated by HPP. For example, Rodriguez et al. showed that HPP under $400 \mathrm{Mpa} / 1$ min performed on persimmon puree could eliminate microbial counts and show no regrowth during storage, and that there was also good physicochemical attributes, phenolic compounds, and antioxidant capacity of the puree which was stable during storage. The HPP, however, was not able to effectively inhibit enzyme activity [7]. Kumari et al. also observed that persimmon pulp treated by HPP under $20^{\circ} \mathrm{C} / 400 \mathrm{Mpa} / 5 \mathrm{~min}$ had a reduced total plate count and yeast mold count [8]. Moreover, José et al. studied HPP under 200 Mpa for improved carotenoid extractability and tannin polymerization in order to improve the functionality and taste of fresh-cut persimmon [9]. Similar results were studied by de Ancos et al. [10], Lucía et al. [11] and Cano et al. [12]. Furthermore, Vázquez et al. explained that HPP affected the structure of persimmon significantly, which influences the integrity of cell walls and membranes, so as to improve the extractability of carotenoid and soluble tannin [13]. Additionally, Hernández-Carrión et al. compared new milk-based persimmon beverages treated by HPP and pasteurization and found that HPP was good for releasing carotenoids from the fruit matrix, precipitating tannins and rheological properties. The untreated and pasteurized persimmon milk-based beverages had either a gel-like structure or became separated out [14]. In conclusion, as a novel and important non-thermal processing, a HPP treatment could guarantee the safety, nutrition and sensory attributes of persimmon and its products, and it has the potential to activate enzymes which are good for persimmon processing; however, no one has previously studied a HPP treatment for the juice yield of persimmon or the quality of persimmon juice. Therefore, this work's purpose was to design a processing technology for persimmon juice which could solve the low juice yield problem and avoid exogenous pectinase from being added. Firstly, three persimmon cultivars were compared and one of them was selected as the appropriate cultivar for persimmon juice processing. Secondly, the impacts of the HPP pre-treatment on the juice yield and pectinases in persimmon pulp were studied to increase the yield and quality of the juice. Finally, the comparison of HPP and TP as the microbial inactivation procedure was completed and the microorganisms, enzymes, color differences and other physicochemical properties (e.g., $\mathrm{pH}$, total soluble solids, clarity, total phenols, ascorbic acid, soluble tannin and antioxidant capacity) in persimmon juice were studied.

\section{Materials and Methods}

\subsection{Materials and Chemicals}

Fresh and mature persimmons of three cultivars were purchased in Beijing market (shown in Figure 1). The "Gongcheng" cultivar was yellowish and crispy, which was harvested in Guangxi, China; the "Mopan" cultivar was orange-red with a thick peel and soft flesh, which was harvested in Beijing, China; and the "Yangfeng" cultivar was a deep orange-red with moderate hardness, which was harvested in Shanxi, China.

The 2,2-diphenyl-1-picrylhydrazyl (DPPH), $( \pm$ )-6-hydroxy-2,5,7,8-tetramethyl-chroman2-carboxylic acid (Trolox), and 2,4,6-tri-2-pyridyl-1,3,5-triazine (TPTZ) were obtained from Sigma Aldrich (St. Louis, MO, USA). High performance liquid chromatography (HPLC)grade acetonitrile, methanol and formic acid were purchased from Thermo Fisher Scientific (Waltham, MA, USA). Other chemicals were obtained from Solarbio (Beijing, China). 

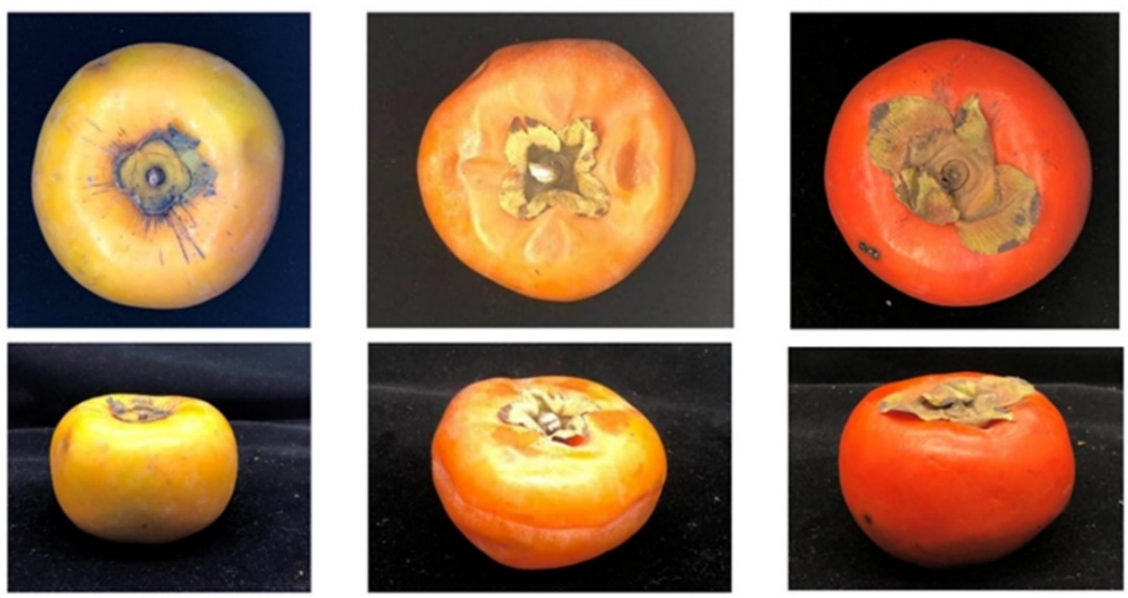

Figure 1. Persimmon (Diospyros kaki L.) cultivars Gongcheng, Mopan and Yangfeng (left to right).

\subsection{Preparation of Persimmon Pulp and Juice}

The persimmons were washed with tap water, cut into pieces and pulped. The persimmon pulp was kept at $20 \pm 1{ }^{\circ} \mathrm{C}$ for $3 \mathrm{~h}$ and then centrifuged under $12,000 \times \mathrm{g} / 10 \mathrm{~min} / 4^{\circ} \mathrm{C}$ (CR21GIII, Hitachi Limited, Japan). The supernatant was gathered as persimmon juice.

\subsection{HPP and TP Treatments of Persimmon Pulp and Juice}

Pre-HPP (100, 200, 300 and $400 \mathrm{MPa}$ for $10 \mathrm{~min} ; 300 \mathrm{MPa}$ for 2, 5, 8 and $10 \mathrm{~min}$ ) and HPP (550 MPa for $5 \mathrm{~min}$ ) treatments of the persimmon pulp and persimmon juice were conducted with a high pressure processing unit (CQC30L-600; Suyuan Zhongtian Scientific Co., Ltd., Beijing, China) at room temperature $\left(20^{\circ} \mathrm{C}\right)$. The holding time of the HPP did not include the time of pressurization and depressurization.

The TP treatments were conducted by keeping the persimmon juice (in $10 \mathrm{~mL}$ polyethylene terephthalate bottles) at $95^{\circ} \mathrm{C}$ for $5 \mathrm{~min}$ in a water bath and then cooling to $20^{\circ} \mathrm{C}$.

The flow chart of the persimmon juice processing in this study is shown in Figure 2.

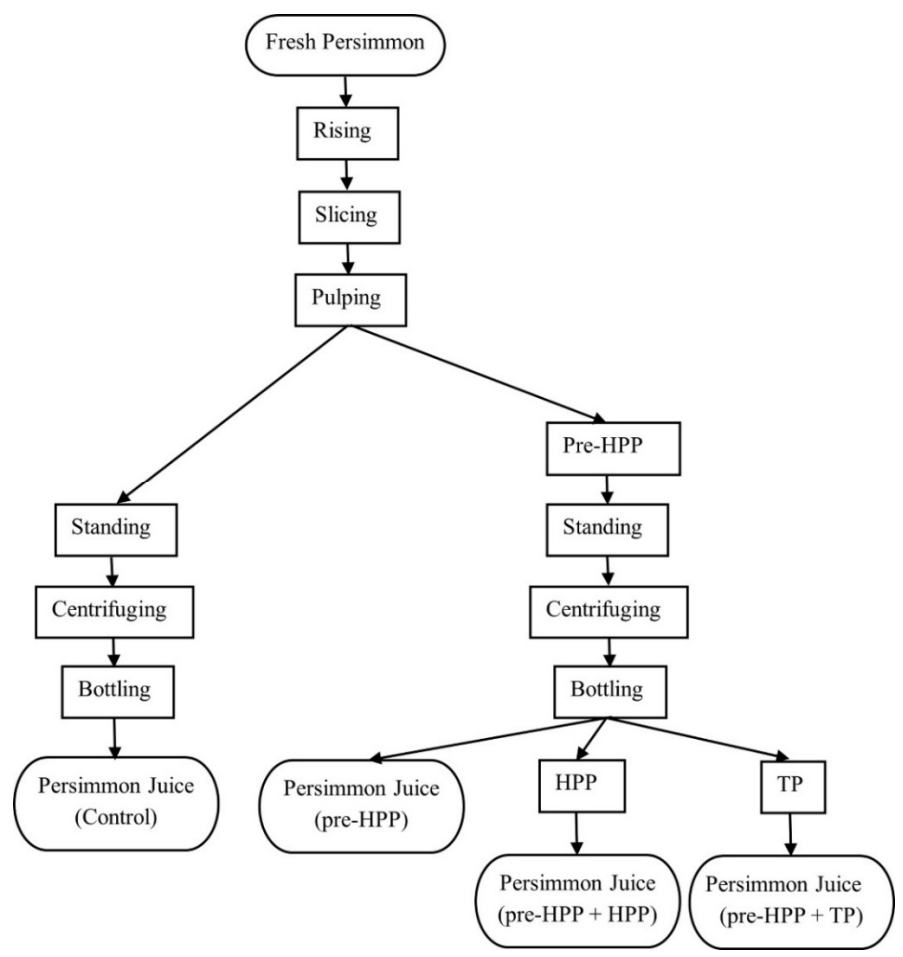

Figure 2. Flow chart of persimmon juice processing. 


\subsection{Determination of $p H$}

The $\mathrm{pH}$ value of the persimmon pulp and juice were measured at $25 \pm 1{ }^{\circ} \mathrm{C}$, with a Thermo Orion $868 \mathrm{pH}$ meter (Thermo Fisher Scientific, Inc., Waltham, MA, USA).

\subsection{Determination of Total Soluble Solids (TSS)}

The TSS of the persimmon pulp and juice were determined at $25 \pm 1{ }^{\circ} \mathrm{C}$ by a WAY-2S Digital Abbe Refractometer (Shanghai Precision \& Scientific Instrument Co., Shanghai, China), and the results were reported as oBrix.

\subsection{Determination of Juice Yield}

The persimmon pulp was centrifuged under $12,000 \times \mathrm{g} / 10 \mathrm{~min} / 4{ }^{\circ} \mathrm{C}$. Then, the supernatant was collected as persimmon juice. The juice yield was calculated using Equation (1), where $M_{\text {juice }}$ is the weight of the persimmon juice and $M_{\text {pulp }}$ is the weight of the persimmon pulp:

$$
\text { Juice yield (\%) }=M_{\text {juice }} / M_{\text {pulp }}
$$

\subsection{Determination of Total Phenols}

The total phenols of the persimmon pulp and juice were measured by Folin-Ciocalteu as described by Kim with some modifications [15]. A $2 \mathrm{~mL}$ amount of persimmon juice or pulp was first added to a vessel with $2 \mathrm{~mL}$ methanol $(80 \%)$ and then extracted for $20 \mathrm{~min}$ with an ultrasonic machine. Then, the mixture was centrifuged under $12,000 \times \mathrm{g} / 10 \mathrm{~min} / 4{ }^{\circ} \mathrm{C}$. The supernatant of $0.4 \mathrm{~mL}$ and $2 \mathrm{~mL}$ Folin-Ciocalteu reagent (both previously diluted ten-fold using distilled water) were mixed with $1.8 \mathrm{~mL}$ of sodium carbonate solution $(7.5 \%)$ and then left for $1 \mathrm{~h}$ in the dark at room temperature. After that, the mixture needed to be measured immediately at $765 \mathrm{~nm}$ using a spectrophotometer (UV-1800, UNICO, Shanghai, China) and the results were reported as a mg of gallic acid equivalent (GAE) per $100 \mathrm{~g}$ juice.

\subsection{Determination of Ascorbic Acid (AA)}

The ascorbic acid levels of the persimmon pulp and juice were determined by a HPLC (LC-20AT, Shimadzu, Kyoto, Japan) equipped with a pump, a UV-Vis detector and a data acquisition system. The chromatographic column was a Venusil XBP C18 column $(4.6 \times 250 \mathrm{~mm}, 5 \mu \mathrm{m})$ from the Angela Company, and the column temperature was $30^{\circ} \mathrm{C}$. The persimmon pulp or juice $(5 \mathrm{~g})$ was mixed with a $1 \%$ formic acid solution $(5 \mathrm{~mL})$. After extraction for $2 \mathrm{~h}$ at $4{ }^{\circ} \mathrm{C}$ and centrifugation under $12,000 \times \mathrm{g} / 10 \mathrm{~min} / 4^{\circ} \mathrm{C}$, the supernatant was filtered through a $0.45 \mu \mathrm{m}$ membrane and analyzed by HPLC. The flow rate was $1 \mathrm{~mL} / \mathrm{min}$, the mobile phase was $10 \mathrm{~mL}$ of acetonitrile in a $90 \mathrm{~mL}$ formic acid solution (1\%), the sample injection volume was $20 \mu \mathrm{L}$ and detection was set at $254 \mathrm{~nm}$ [16].

\subsection{Sensory Evaluation}

Sensory evaluation of persimmon juices from the 3 different cultivars were carried out by ten panelists and were conducted following the protocol in NY 82.2-1988 [17] with some modifications. The persimmon juice samples were placed in small plastic cups (50 mL juice per cup) and identified with random three-digit codes. All samples were evaluated at about $18{ }^{\circ} \mathrm{C}$. The panelists scored the samples for color, flavor, mouthfeel, appearance, and acceptability. Each attribute was scored from 1 to 4 . Higher numbers represented a stronger performance. The results were reported as the total score of 5 attributes for the persimmon juice from each cultivar.

The sensory evaluation was carried out under low intensity light conditions to guarantee correct color and appearance evaluation. For acceptability, the panelists first evaluated the flavor and then tasted samples to evaluate the mouthfeel. It should be noted that the panelists were instructed to cleanse their palate with taste-free water (Wahaha, Hangzhou, China) after evaluating each sample. 


\subsection{Determination of Pectin Methylesterase (PME) Activity}

The PME activity of the persimmon juice and pulp were determined by measuring the release of acid at $\mathrm{pH} 7.5 / 30^{\circ} \mathrm{C}$, as described by Bi with some modifications [18]. Persimmon pulp or juice $(5 \mathrm{~g})$ mixed with a $0.02 \mathrm{M}$ Tris- $\mathrm{HCl}$ buffer $(10 \mathrm{~mL}$, $\mathrm{pH} 7.5$, containing $0.1 \mathrm{M}$ $\mathrm{NaCl}$ ) was kept for $12 \mathrm{~h}$ at $4{ }^{\circ} \mathrm{C}$, and then centrifuged at $12,000 \times \mathrm{g}$ for $10 \mathrm{~min}$ at $4{ }^{\circ} \mathrm{C}$. The PME activity was detected with an automatic potentiometric titrator (751 GPD Titrino, Metrohm, Herisau, Switzerland). The supernatant $(5 \mathrm{~mL})$ was added into a $60 \mathrm{~mL} \mathrm{1 \%}$ pectin solution $(w / v, \mathrm{pH} 7.5$, containing $0.1 \mathrm{M} \mathrm{NaCl}) . \mathrm{NaOH}(0.05 \mathrm{M})$ was automatically added to keep the solution $\mathrm{pH}$ at 7.5. The slope of the linear portion of the graph of $V_{\mathrm{NaOH}}$ (in milliliters) versus $t$ (in minutes) was obtained to calculate the PME activity using the following Equation (2), where $C_{\mathrm{NaOH}}$ is the $\mathrm{NaOH}$ concentration $(0.05 \mathrm{M})$, and $V_{\text {sample }}$ is the sample volume ( $5 \mathrm{~mL}$ of the supernatant). The results were expressed as PME activity units $\left(\mathrm{mmoL} \cdot \mathrm{L}^{-1} \cdot \mathrm{min}^{-1}\right)$, where one unit equals $1 \mathrm{mmoL} \mathrm{NaOH}$ consumed per liter sample per minute:

$$
\text { PME activity }=\text { Slope } \times \mathrm{C}_{\mathrm{NaOH}} / V_{\text {sample }}
$$

\subsection{Determination of Polygalacturonase (PG) Activity}

The PG activity of the persimmon pulp or juice were determined as the method described by Amnuaysin with some modifications [19]. Persimmon pulp or juice (2 g) was mixed with $6 \% \mathrm{NaCl}(6 \mathrm{~mL}$, containing $0.6 \%$ EDTA and $1 \% \mathrm{PVP})$ and centrifuged under $12,000 \times \mathrm{g} / 20 \mathrm{~min} / 4^{\circ} \mathrm{C}$. After that, $0.1 \mathrm{~mL}$ supernatant (previously diluted ten-fold using distilled water) was added into a $1.0 \mathrm{~mL}$ pectin solution $(0.5 \%, w / v)$ and kept at $37^{\circ} \mathrm{C}$ for $30 \mathrm{~min}$. After adding $0.9 \mathrm{~mL}$ DNS reagent, the samples were kept in a boiling water bath for $5 \mathrm{~min}$ and then measured at $540 \mathrm{~nm}$ using a UV-1800 spectrophotometer (UNICO, Shanghai, China). The results were expressed as PG activity units $\left(\mathrm{U} \cdot \mathrm{g}^{-1}\right)$, where one unit equals $1 \mathrm{~g}$ free galacturonic acid produced by the decomposition of pectin at $37^{\circ} \mathrm{C}$ per gram of fresh sample per minute.

\subsection{Microbiological Analysis}

To detect natural microorganisms in the persimmon juice, the total plate count method was used [20]. Samples were diluted with a sterile $0.9 \% \mathrm{NaCl}$ solution one by one, followed by plating in a $1.0 \mathrm{~mL}$ dilution into duplicate plates of appropriate agar. Plate count agar (Beijing Solarbio Science \& technology Co. Ltd., Beijing, China) was used for the total aerobic bacteria (TAB) counting after incubation at $37^{\circ} \mathrm{C}$ for $48 \pm 2 \mathrm{~h}$. Rose Bengal agar (Beijing Solarbio Life Science Co. Ltd., Beijing, China) was used for the yeasts and molds (Y\&M) counting after incubation at $28^{\circ} \mathrm{C}$ for $72 \pm 2 \mathrm{~h}$. The colonies were counted and $\log 10 \mathrm{~N}$ was used for describing the inactivation effect, where $N$ is the number of microorganisms.

\subsection{Determination of Water-Soluble Pectin}

The extraction and measurements of soluble pectin in the persimmon juice were described by Rose et al. with some modifications [21]. Persimmon juice (10 g) was added to $95 \%$ ethanol $(30 \mathrm{~mL})$, kept in a boiling water bath for $20 \mathrm{~min}$, and then filtered with a G4 sand core funnel. After being dried at $35^{\circ} \mathrm{C}$ for $24 \mathrm{~h}$, the powder $(20 \mathrm{mg})$ was added to $7.5 \mathrm{~mL}$ of distilled water and centrifuged under $12,000 \times \mathrm{g} / 10 \mathrm{~min}$. The supernatant $(1 \mathrm{~mL})$ was mixed with concentrated sulfuric acid $(10 \mathrm{~mL})$ and kept at $85^{\circ} \mathrm{C}$ for $25 \mathrm{~min}$. After adding $0.8 \mathrm{~mL}$ Carbazole-ethanol $(0.15 \%)$, the solution was measured at $540 \mathrm{~nm}$ using a UV-1800 spectrophotometer (UNICO, Shanghai, China). The results were expressed as micrograms of galacturonic acid per gram of fresh weight.

\subsection{Determination of Soluble Tannin}

The soluble tannin of the persimmon juice was determined by a HPLC (LC-20AT, Shimadzu, Japan) equipped with a pump, a UV-Vis detector and a data acquisition system. The chromatographic column was a Venusil XBP C18 column $(4.6 \times 250 \mathrm{~mm}, 5 \mu \mathrm{m})$ from the 
Angela Company, and the column temperature was $30^{\circ} \mathrm{C}$. The persimmon juice $(5 \mathrm{~g})$ was mixed with ultrapure water $(5 \mathrm{~mL})$. After extraction for $30 \mathrm{~min}$ at $50^{\circ} \mathrm{C}$ and centrifugation under $12,000 \times \mathrm{g} / 10 \mathrm{~min} / 4{ }^{\circ} \mathrm{C}$, the supernatant was filtered through a $0.45 \mu \mathrm{m}$ membrane and analyzed by HPLC. The flow rate was $1 \mathrm{~mL} / \mathrm{min}$, the mobile phase was $20 \mathrm{~mL}$ of ultrapure water in $80 \mathrm{~mL}$ methanol, the sample injection volume was $20 \mu \mathrm{L}$ and detection was set at $275 \mathrm{~nm}$ [22].

\subsection{Determination of Antioxidant Activity \\ 2.15.1. DPPH Radical Scavenging Assay (DPPH)}

This assay was based on measuring the scavenging ability of antioxidants to the stable radical $\bullet$ DPPH [23]. The extract $(200 \mu \mathrm{L})$ was mixed with $0.14 \mathrm{mM}$ methanolic $\bullet$ DPPH solution $(4 \mathrm{~mL})$. A control reaction was prepared with $200 \mu \mathrm{L}$ of methanol mixed with $4 \mathrm{~mL}$ of a $0.14 \mathrm{mM}$ methanolic $\bullet \mathrm{DPPH}$ solution. The samples were kept in the dark for $45 \mathrm{~min}$ at room temperature before measuring the decrease in the absorption at $517 \mathrm{~nm}$ with a UV-1800 spectrophotometer (UNICO, Shanghai, China). Radical scavenging activity was calculated by Equation (3), where $A_{0}$ is the absorbance of the control and $A_{S}$ is the absorbance in the presence of the persimmon extract. The results were expressed as milligrams of Trolox equivalents per $100 \mathrm{~mL}$ of persimmon juice (TE/100 mL):

$$
\text { Radical scavenging activity }(\%)=\left(A_{S}-A_{0}\right) / A_{0} \times 100
$$

\subsubsection{Ferric Reducing/Antioxidant Power Assay (FRAP)}

This assay referred to Aljadi and Kamaruddin with some modifications [24]. The freshly prepared FRAP solution contained $0.3 \mathrm{~mol} / \mathrm{L}$ acetate buffer $(25 \mathrm{~mL}, \mathrm{pH} 3.6)$, $2.5 \mathrm{~mL}$ of $10 \mathrm{mmoL} / \mathrm{L} \mathrm{TPTZ} \mathrm{(dissolved} \mathrm{in} 40 \mathrm{mmoL} / \mathrm{L} \mathrm{HCl}$ ), and $20 \mathrm{mmoL} / \mathrm{L}$ ferric chloride $(2.5 \mathrm{~mL})$.

The FRAP solution $(4 \mathrm{~mL})$ was mixed with the extract $(100 \mu \mathrm{L})$, and the mixture was kept under $37^{\circ} \mathrm{C} / 10 \mathrm{~min}$. The ferric reducing ability was measured by using the absorbance at $593 \mathrm{~nm}$ using a UV-1800 spectrophotometer (UNICO, Shanghai, China). The results were expressed as milligrams TE/100 mL.

\subsection{Determination of PPO and POD Activity}

The enzymes were extracted and determined according to Zhang et al. with some modifications [25]. For the enzyme extraction, $2.5 \mathrm{~g}$ of persimmon juice was mixed with a $5 \mathrm{~mL}$ buffer $\left(0.2 \mathrm{M}, \mathrm{pH} 6.5\right.$, phosphate buffer with $4 \%(w / v)$ PVPP). After standing at $4{ }^{\circ} \mathrm{C}$ for $1 \mathrm{~h}$, the mixture was centrifuged under $12000 \mathrm{~g} / 10 \mathrm{~min} / 4^{\circ} \mathrm{C}$, and the supernatant was collected and analyzed for enzyme activity. The PPO and POD activity were determined by a Spark $10 \mathrm{M}$ microplate spectrophotometer (Tecan, Mennendorf, Switzerland) based on the absorbances of $420 \mathrm{~nm}$ and $470 \mathrm{~nm}$, respectively. The reaction mixture for the PPO was $10 \mu \mathrm{L}$ of extract and $190 \mu \mathrm{L}$ of catechol $(0.1 \mathrm{M})$ in a phosphate buffer $(0.2 \mathrm{M}, \mathrm{pH} 6)$ solution. The reaction mixture for the POD was $190 \mu \mathrm{L}$ of guaiacol $(1.0 \%, \mathrm{~m} / v$, dissolved in a $0.2 \mathrm{M}$ phosphate buffer, $\mathrm{pH} 6), \mathrm{H}_{2} \mathrm{O}_{2}(1 \%, \mathrm{~m} / \mathrm{v})$, and $10 \mu \mathrm{L}$ of the diluent extract.

\subsection{Color Assessment}

The color assessment was carried out at $25 \pm 2{ }^{\circ} \mathrm{C}$ using a color difference meter (Color Quest XE, Hunter Associates Laboratory Inc., Reston, VA, USA). The measured parameters were $L^{*}$ for lightness, $a^{*}$ for redness, and $b^{*}$ for yellowness. In addition, the total color difference $(\Delta E)$ was calculated using Equation (4), where $L_{0}{ }^{*}, a_{0}{ }^{*}$, and $b_{0}{ }^{*}$ were the control values for the untreated juice:

$$
\Delta E=\left[\left(L^{*}-L_{0} *\right)^{2}+\left(a^{*}-a_{0} *\right)^{2}+\left(b^{*}-b_{0}^{*}\right)^{2}\right]^{1 / 2}
$$

\subsection{Determination of Browning Degree (BD)}

The determination of BD was described by Meydav with some modifications [26]. Persimmon juice $(5 \mathrm{~mL})$ was mixed with ethanol $(5 \mathrm{~mL})$ and centrifuged under 
$12,000 \times \mathrm{g} / 10 \mathrm{~min} / 4{ }^{\circ} \mathrm{C}$. The $\mathrm{BD}$ was determined by measuring the absorbance of the supernatant at $420 \mathrm{~nm}$ using a UV-1800 spectrophotometer (UNICO, Shanghai, China).

\subsection{Determination of Clarity}

The clarity of the persimmon juice was determined by measuring the transmittance of juice at $625 \mathrm{~nm}$ using a UV-1800 spectrophotometer (UNICO, Shanghai, China) [27].

\subsection{Statistical Analysis}

All experiments were made in triplicate. The data were analyzed using the Statistical Program for Social Sciences (SPSS 23, Chicago, IL, USA) software for the analysis of variance and Duncan's test. The significance was established at $p<0.05$.

\section{Results and Discussion}

\subsection{Differences on Physical and Chemical Indexes of Three Persimmon Cultivars}

In order to select a suitable persimmon cultivar for juicing, some basic indexes of three persimmon cultivars including "Gongcheng" from Guangxi, "Mopan" from Beijing and "Yangfeng" from Shanxi were compared in Table 1. The most important index for juicing is the juice yield, which was $41.03 \%$ in the Gongcheng persimmon, and which was the highest of the three cultivars. The total phenol content in the "Gongcheng" was significantly higher than that in the other two cultivars, reaching $6.78 \mathrm{mg}$ GAE/100 $\mathrm{g}$ and the content of AA in the "Gongcheng" was in the middle range of the three. Using a sensory score to evaluate the different cultivars (details shown in Figure 3), "Gongcheng" received the highest score as shown in Table 1. After synthetical analysis of the juice yield and the nutrition content, the "Gongcheng" was recommended to be used as the raw material for the persimmon juice in the following study.

Table 1. Physical and chemical indexes of three different persimmon cultivars.

\begin{tabular}{cccc}
\hline & Gongcheng (Guangxi) & Mopan (Beijing) & Yangfeng (Shanxi) \\
\hline Juice yield (\%) & $41.03 \pm 0.75 \mathrm{a}$ & $21.84 \pm 2.41 \mathrm{~b}$ & $10.27 \pm 0.47 \mathrm{c}$ \\
pH & $5.83 \pm 0.01 \mathrm{c}$ & $6.00 \pm 0.01 \mathrm{~b}$ & $6.28 \pm 0.02 \mathrm{a}$ \\
TSS (oBrix) & $14.60 \pm 0.10 \mathrm{c}$ & $15.00 \pm 0.10 \mathrm{~b}$ & $17.30 \pm 0.10 \mathrm{a}$ \\
Total phenols (mg GAE/100 g FW) & $6.78 \pm 0.33 \mathrm{a}$ & $2.78 \pm 0.28 \mathrm{~b}$ & $1.93 \pm 0.17 \mathrm{c}$ \\
Ascorbic acid (mg/100 g FW) & $28.32 \pm 1.42 \mathrm{~b}$ & $18.25 \pm 2.79 \mathrm{c}$ & $97.53 \pm 3.40 \mathrm{a}$ \\
Sensory evaluation & 16.70 & 15.60 & 14.50
\end{tabular}

All data were the means $\pm \mathrm{SD}, n=3$. Different letters in the same row indicate a significant difference $(p<0.05)$. TSS: total soluble solids.

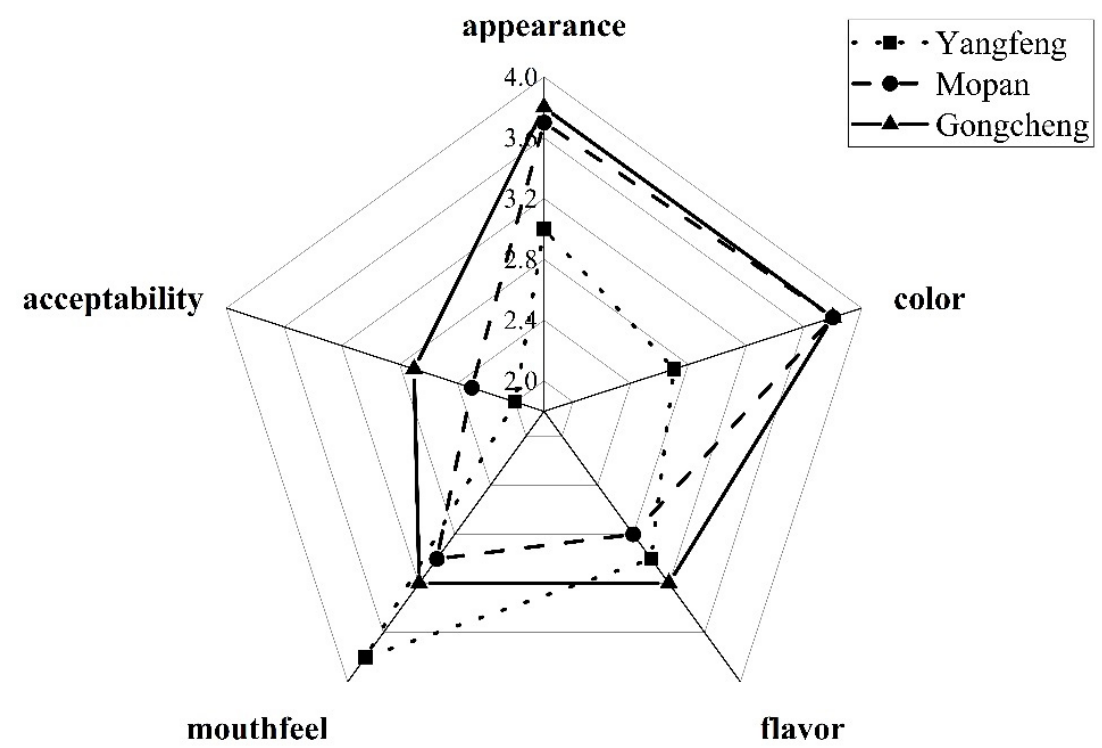

Figure 3. Sensory evaluation of juice from three persimmon cultivars. 


\subsection{Effects of Different Pre-HPP Treatment Pressure and Time on Juice Yield, PME and PG Activity of Persimmon Pulp}

As shown in Figure 4, the pre-treatment of the persimmon pulp by HPP could increase the juice yield and PME activity, but slightly decrease the PG activity. Compared with the pre-HPP treatment of 100, 200, 300 and $400 \mathrm{MPa}$ for $10 \mathrm{~min}$, the juice yield maximum increased by $22.42 \%$ after $300 \mathrm{MPa} / 10 \mathrm{~min}$. For the juice yield relative enzyme, the activity of the PME and PG was increased by $27.4 \%$ and slightly decreased by $5.8 \%$ individually after $300 \mathrm{MPa} / 10$ min pre-treatment. A similar phenomenon was also reported elsewhere that the PME in tomato juice was activated by $300 \mathrm{MPa} / 10 \mathrm{~min} / 25^{\circ} \mathrm{C}$ with an almost $50 \%$ increase and the PG was decreased by approximately $15 \%$ [28]. Liu et al. reported that PME activity was activated by $10-40 \%$ when mango pulp was treated with $300-500 \mathrm{MPa}$ for $5 \mathrm{~min}$, while the residual activity of mango pulp treated with $110^{\circ} \mathrm{C} / 8.6 \mathrm{~s}$ was only $3 \%$ of the control group [20].

(a)

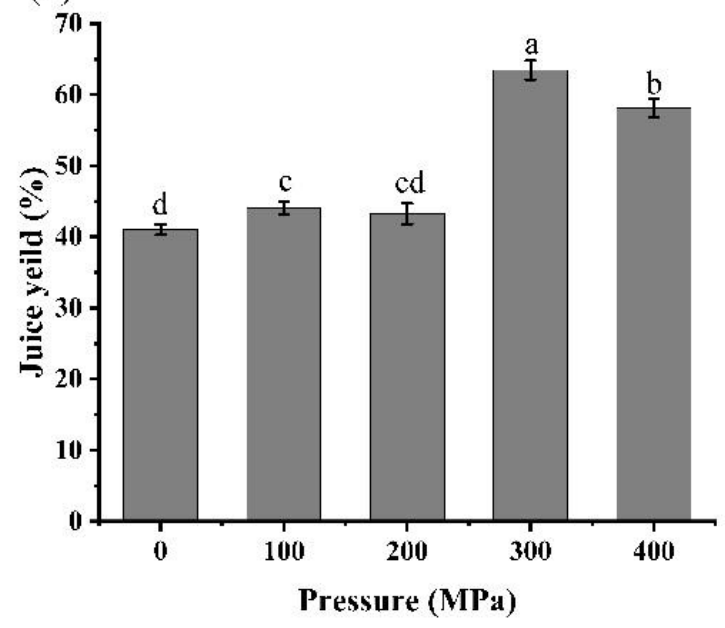

(b)

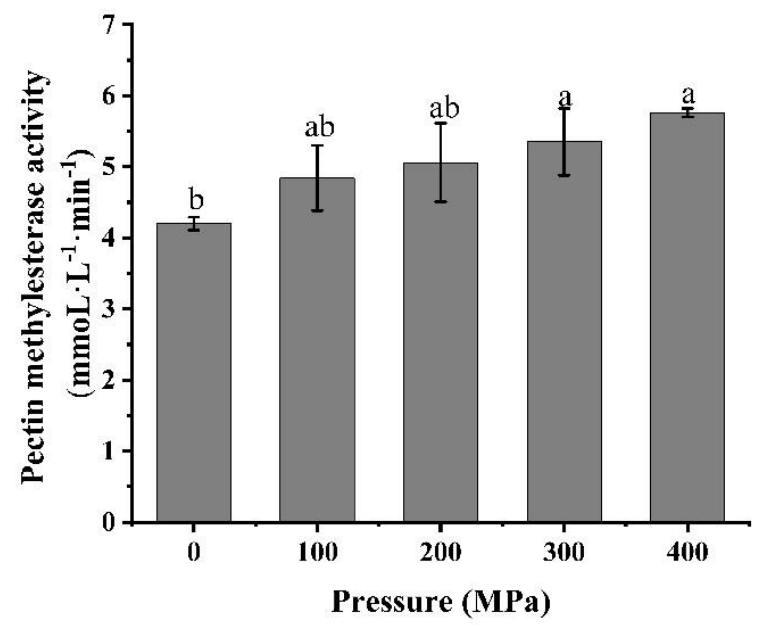

(c)

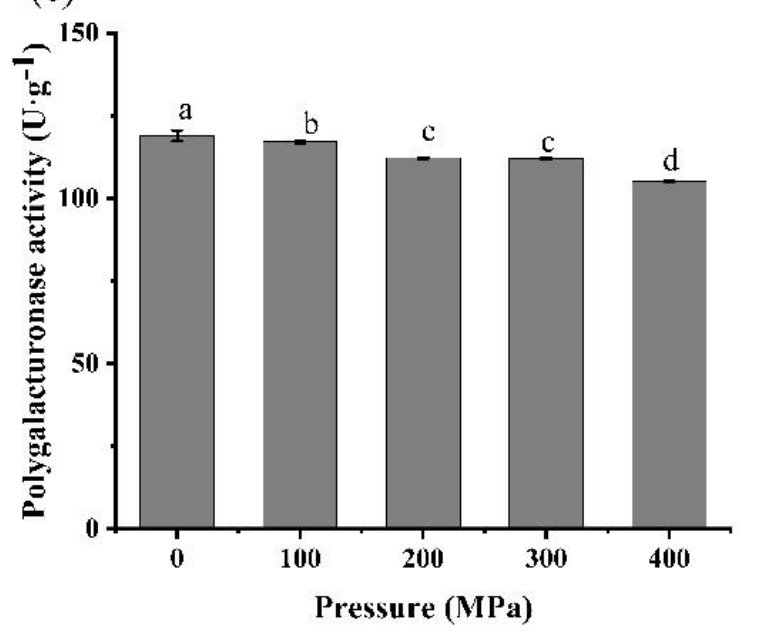

Figure 4. Effects of different pre-HPP treatment pressure on (a) juice yield, (b) pectin methylesterase activity, and (c) polygalacturonase activity in "Gongcheng" persimmon pulp for $10 \mathrm{~min}$. (Different letters in the same graphic indicate a significant difference $(p<0.05)$.)

The activation of the PME by pre-HPP could be due to an increase of the de-esterification reaction rate by volume being reduced resulting from electrostriction [5]. Moreover, the HPP treatment could affect the tertiary and quaternary structure of the enzyme by modifying the enzyme's electrostatic, hydrophobic interaction and hydrogen bonding, exposing more active sites or increasing the size of existing active sites [29], thereby promoting 
endogenous PME demethylation esterification. The changes of the substrate molecules induced by HPP was also suggested as a reason for the increased rate of PME catalyzed reactions, e.g., the disruption of membranes, releasing the membrane-bound PME and promoting the binding of enzymes and substrates [28]. Crelier et al. reported that the PG in tomatoes had a certain stability under high pressure, and its thermal stability was stronger than that of the PME-heat treatment alone or HPP treatment at room temperature could not inactivate the enzyme effectively - which was consistent with the experimental results $[30,31]$.

The increase in PME activity had positive influence on the juice yield, as the PME could break down the pectin molecules so that the structure-broken cells released more juice. In detail, the pectin molecule is a polysaccharide chain formed by the linear polymers of D-galacturonic acid with different esterification degrees with $\alpha-1,4$ glycosidic linkages. It has a very high colloidal stability and water-binding capacity, which makes it difficult for fruit juice to flow out during the process of fruit extrusion [32]. The PME de-esterifies the methyl groups on the galacturonic acid backbone of pectin which enhances the juice yield [33]. Moreover, the PG catalyzes the hydrolytic cleavage of the glycosidic $\alpha$-D-(1-4) bonds in the pectic acid and leads to a viscosity decrease, hence the juice yield increased as well. Low ester pectin produced by the PME de-esterifying would also combine with $\mathrm{Ca}^{2+}$ and form the $\mathrm{Ca}^{2+}$ pectate gels which influences the juice quality; however, the retained PG could compete with the $\mathrm{Ca}^{2+}$ inducing the $\mathrm{Ca}^{2+}$ pectate gels and therefore guarantee good quality of the persimmon juice.

As the activation of the PME and retention of the PG by the pre-HPP treatment at $300 \mathrm{MPa}$ could lead to an increased yield in the persimmon juice, different treatment times at $300 \mathrm{MPa}$ were compared in Figure 5. The juice yield of the persimmon pulp treated with $300 \mathrm{MPa}$ for 2, 5, 8 and $10 \mathrm{~min}$, were all significantly higher than that of the control. After $300 \mathrm{MPa} / 8 \mathrm{~min}$, the persimmon juice yield was the highest, which was 1.6 times higher than that of the control group. The PME activity of the persimmon pulp treated with $300 \mathrm{MPa}$ for 5, 8 and $10 \mathrm{~min}$, was significantly increased and the PME in samples treated by $300 \mathrm{MPa} / 5$ min was the highest with no significant difference compared with the 8 and $10 \mathrm{~min}$ samples, which was nearly $26 \%$ higher than that of the control. The activity of PG in the persimmon pulp did not change after $300 \mathrm{MPa}$ for 2 and $8 \mathrm{~min}$, while it slightly increased after $5 \mathrm{~min}$ and decreased after $10 \mathrm{~min}$. Since the persimmon pulp treated by pre-HPP (300 MPa/8 min) achieved the highest juice yield, and increased PME activity and maintained PG activity, a pre-HPP of $300 \mathrm{MPa} / 8 \mathrm{~min}$ was recommended to be used in the pre-treatment of persimmon juice.

(a)

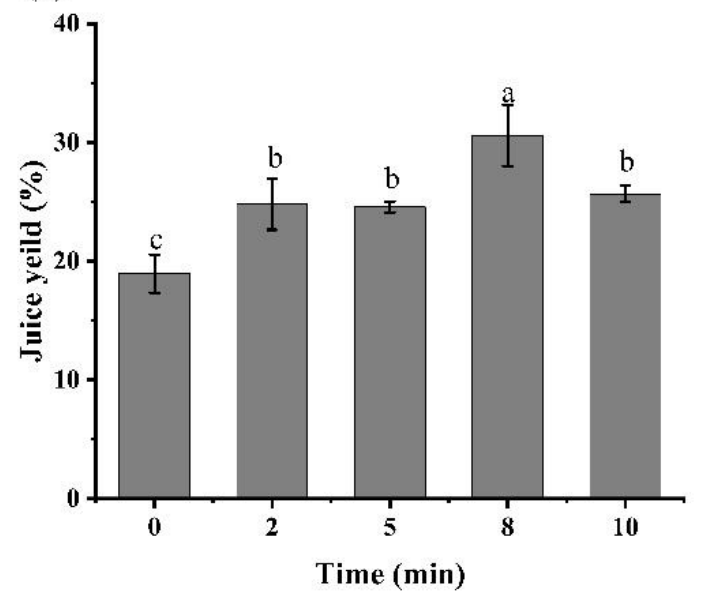

(b)

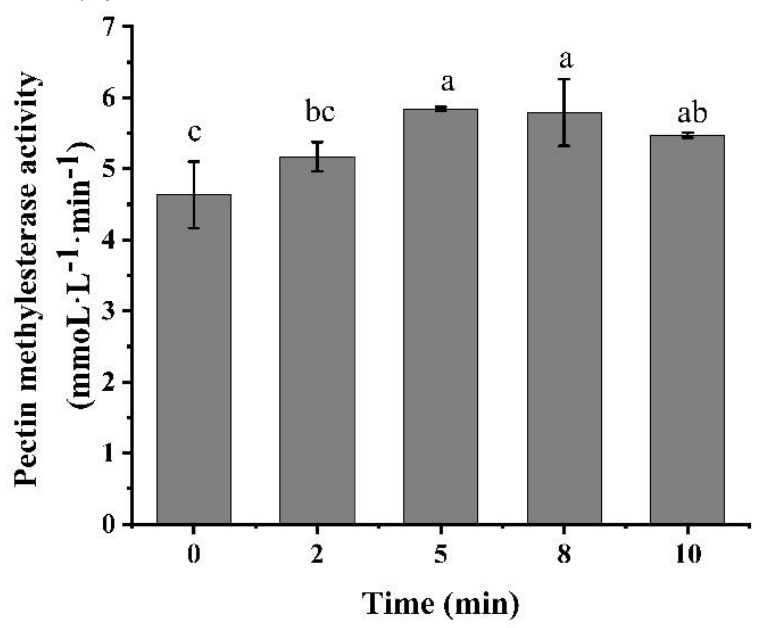

Figure 5. Cont. 


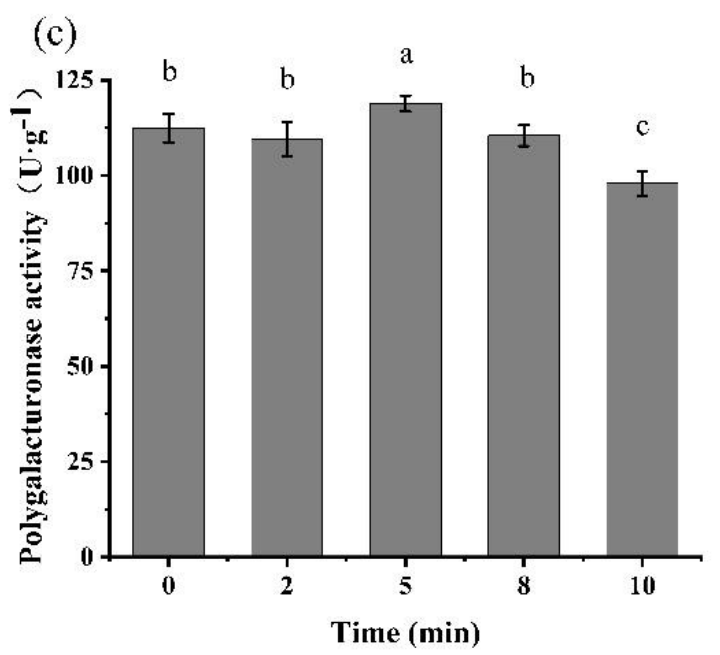

Figure 5. Effects of different pre-HPP treatment times on (a) juice yield, (b) pectin methylesterase activity, and (c) polygalacturonase activity in persimmon pulp under $300 \mathrm{MPa}$. (Different letters in the same graphic indicate a significant difference $(p<0.05)$.).

\subsection{Effects of HPP and TP on Microorganism, $p H$ and TSS of Persimmon Juice}

As shown in Table 2, the initial total aerobic bacteria (TAB) in the persimmon juice were $5.61 \mathrm{lg}$ CFU $/ \mathrm{mL}$, and after pre-HPP, it was still more than $5 \mathrm{lg} \mathrm{CFU} / \mathrm{mL}$. The TAB decreased to $1.29 \mathrm{lg} \mathrm{CFU} / \mathrm{mL}$ after pre-HPP plus HPP (550 MPa/5 min), which meets the standard of the National Food Safety Standard-Beverage GB 7101-2015 in China. In the pre-HPP plus TP $\left(95^{\circ} \mathrm{C} / 5 \mathrm{~min}\right)$ samples, the TAB was not detected. No yeast and molds were detected in all the samples treated by the pre-HPP plus HPP or pre-HPP plus TP. The values of $\mathrm{pH}$ and TSS in the pre-HPP (300 MPa/8 min) treated juices were unchanged; however, in samples of the pre-HPP plus HPP and pre-HPP plus TP, the $\mathrm{pH}$ value decreased significantly. The reduction in $\mathrm{pH}$ was explained by the degradation of tissue when the samples were treated with a higher pressure again [34].

Table 2. Effects of different treatments on microbial, $\mathrm{pH}$, TSS and juice yield levels of persimmon juice.

\begin{tabular}{|c|c|c|c|c|}
\hline Treatments & Control & Pre-HPP (300 MPa/8 Min) & $\begin{array}{l}\text { Pre-HPP + HPP (300 MPa/8 min } \\
\text { + } 550 \mathrm{MPa} / 5 \mathrm{Min})\end{array}$ & $\begin{array}{c}\text { Pre-HPP }+ \text { TP }(300 \mathrm{MPa} / 8 \mathrm{~min}+ \\
\left.95^{\circ} \mathrm{C} / 5 \mathrm{Min}\right)\end{array}$ \\
\hline TAB $(\lg$ CFU / mL) & $5.61 \pm 0.17 \mathrm{a}$ & $5.25 \pm 0.03 b$ & $1.29 \pm 0.08 \mathrm{c}$ & ND \\
\hline Y\&M (lg CFU/mL) & ND & ND & ND & ND \\
\hline $\mathrm{pH}$ & $5.96 \pm 0.10 a$ & $5.94 \pm 0.09 \mathrm{a}$ & $5.63 \pm 0.03 b$ & $4.87 \pm 0.08 c$ \\
\hline TSS (oBrix) & $15.2 \pm 0.3 \mathrm{a}$ & $14.7 \pm 0.3 \mathrm{ab}$ & $14.4 \pm 0.3 \mathrm{~b}$ & $14.6 \pm 0.4 \mathrm{ab}$ \\
\hline Juice yield (\%) & $48.9 \pm 0.1$ & $60.1 \pm 1.4$ & $60.1 \pm 1.4$ & $60.1 \pm 1.4$ \\
\hline
\end{tabular}

All data were the means $\pm \mathrm{SD}, n=3$. Different letters in the same row indicate a significant difference $(p<0.05)$. HPP: high pressure processing; TP: thermal processing; TAB: total aerobic bacteria; Y\&M: yeast and molds; TSS: total soluble solids; ND: not detected.

\subsection{Effects of HPP and TP on PME, PG, and Water-Soluble Pectin in Persimmon Juice}

In Figure 6a, after a pre-HPP treatment at $300 \mathrm{MPa} / 8 \mathrm{~min}$, the PME activity in the persimmon juice significantly decreased from $5.80 \pm 0.14 \mathrm{mmoL} \cdot \mathrm{L}^{-1} \cdot \mathrm{min}^{-1}$ to $3.72 \pm 0.24 \mathrm{mmoL} \cdot \mathrm{L}^{-1} \cdot \mathrm{min}^{-1}$, which is inconsistent with a previous study that observed PME activity in persimmon pulp significantly increased from $4.20 \pm 0.09 \mathrm{mmoL} \cdot \mathrm{L}^{-1} \cdot \mathrm{min}^{-1}$ to $5.35 \pm 0.47 \mathrm{mmoL} \cdot \mathrm{L}^{-1} \cdot \mathrm{min}^{-1}$ (as shown in Figure $4 \mathrm{~b}$ ). The reason for this inconsistency with the previous study was probably due to the different initial status of the PME in the persimmon raw material. A higher maturity of persimmon was used in this part of the study compared with the previous study, with most of the PME existing as the unbound stage, hence the initial PME activity was higher than the raw material with a lower maturity. Based on previous discussion, activation of the PME by the pre-HPP was probably mainly due to the HPP releasing the membrane-bound PME and promoting the binding of enzymes and substrates. According to the results in this study, it is likely difficult for 
the extra membrane-bound PME in higher mature persimmons to dissolve in the system after a pre-HPP treatment. On the other hand, HPP may have changed the construction of the PME, which caused the decrease in PME activity in this study. Although no increase in PME activity was found in this study, the juice yield still increased (Table 2), indicating that the acceleration of the PME and PG reaction by the HPP played an important role in increasing the juice yield.

(a)

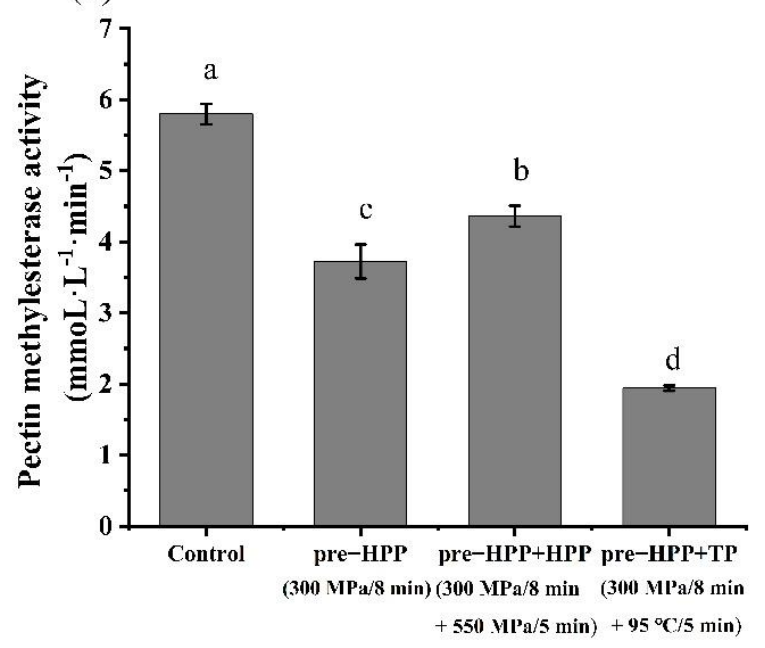

(c)

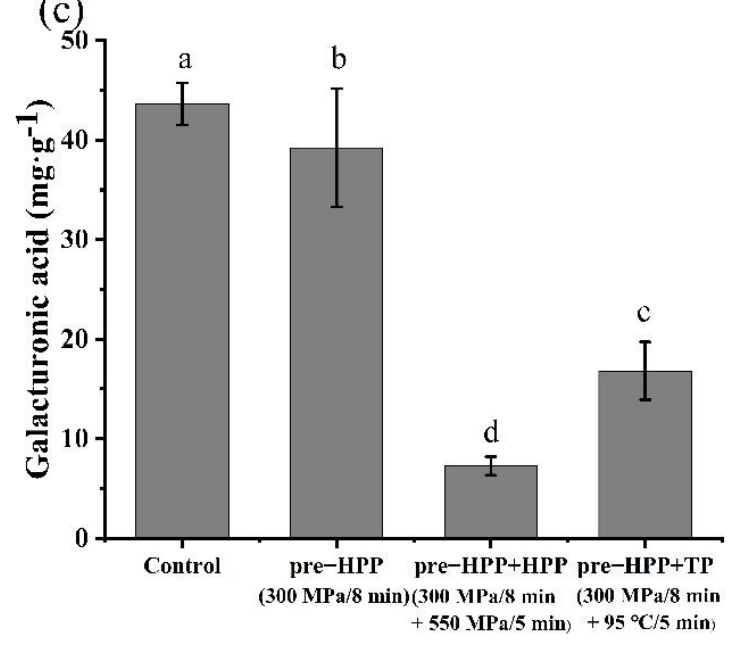

(b)

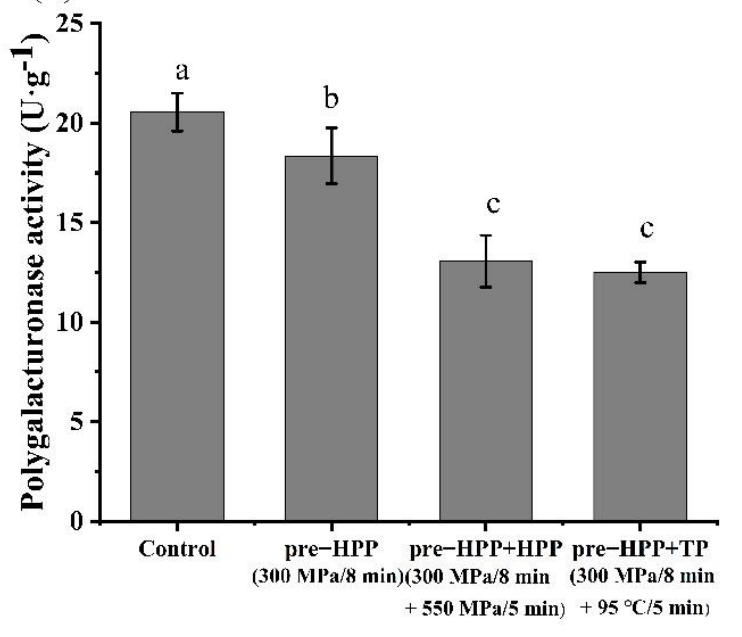

Figure 6. Effects of different treatments on (a) pectin methylesterase activity, (b) polygalacturonase activity, and (c) galacturonic acid in persimmon juice. (Different letters in the same graphic indicate a significant difference $(p<0.05)$.)

After the pre-HPP plus HPP, PME activity in the persimmon juice significantly increased by $17.2 \%$ compared with the pre-HPP treated samples, which was probably due to the further activation of PME in the persimmon juice after second round of HPP, whereas only $52.15 \%$ was left after thermal processing. Compared with the control group, the activity of the PG in the persimmon juice decreased by $10.6 \%$ significantly after the pre-HPP (300 MPa/ $8 \mathrm{~min}$ ), and all decreased to around $60 \%$ of the control after the pre-HPP plus HPP and pre-HPP plus TP, indicating that all of the three treatments could well retain the activity of the PG which is good for the juice yield.

After the pre-HPP, pre-HPP plus HPP and pre-HPP plus TP, the soluble pectin content in the persimmon juice all decreased significantly, which was possibly due to the enzymatic hydrolysis of the pectin or the formation of a pectin-tannin complex. In the pre-HPP plus HPP treated samples, the pectin was the lowest and decreased to $16.66 \%$ of the control group, with a higher PME activity than the other two treatments. This suggests 
that the higher enzyme activity favors the hydrolysis of pectin. The TP could trigger the degradation of the pectin by $\beta$-elimination, especially when the $\mathrm{pH}$ is higher than 4.5 [35].

\subsection{Effects of HPP and TP on Total Phenols, Ascorbic Acid, Antioxidant Capacity and Soluble Tannin in Persimmon Juice}

HPP could well retain the content of total phenols and AA in persimmon juice. After pre-HPP and pre-HPP plus HPP, the total phenol content of the persimmon juice did not change significantly (Figure 7a), while in the pre-HPP plus TP treated samples, it was decreased significantly to $66.48 \%$ of the control group. The samples treated by the pre-HPP and pre-HPP plus HPP showed no significant difference in AA content, while in the preHPP plus TP treated samples, the AA content decreased by $17.02 \%$ (Figure $7 \mathrm{~b}$ ). A large number of studies have reported that heat treatment has a destructive effect on AA, while HPP treatment could maintain the AA content well. Patras et al. showed that the levels of phenols in strawberry and blackberry purées treated at $600 \mathrm{MPa}$ increased significantly as compared to unprocessed purée [16], and that a HPP at a different pressure did not cause any significant change in AA, while following thermal processing the AA degradation was $21 \%$ as compared to unprocessed purées.

(a)

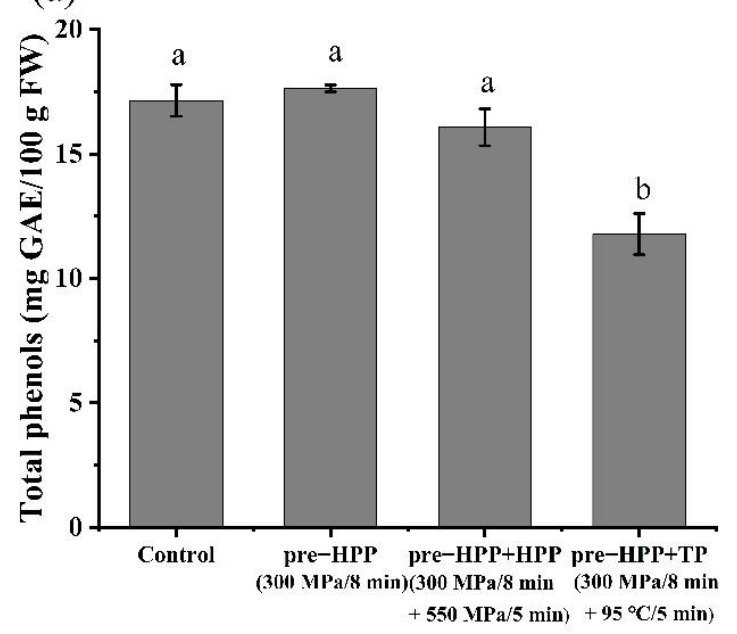

(c)

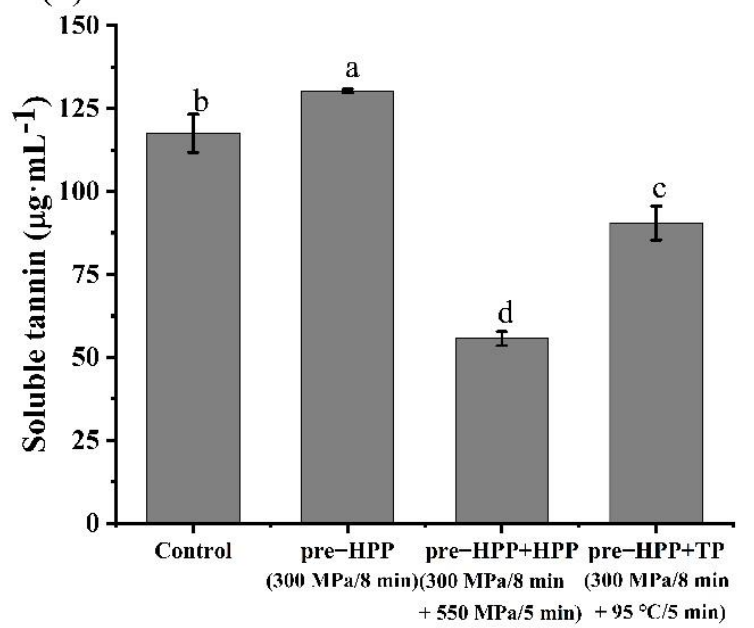

(b)

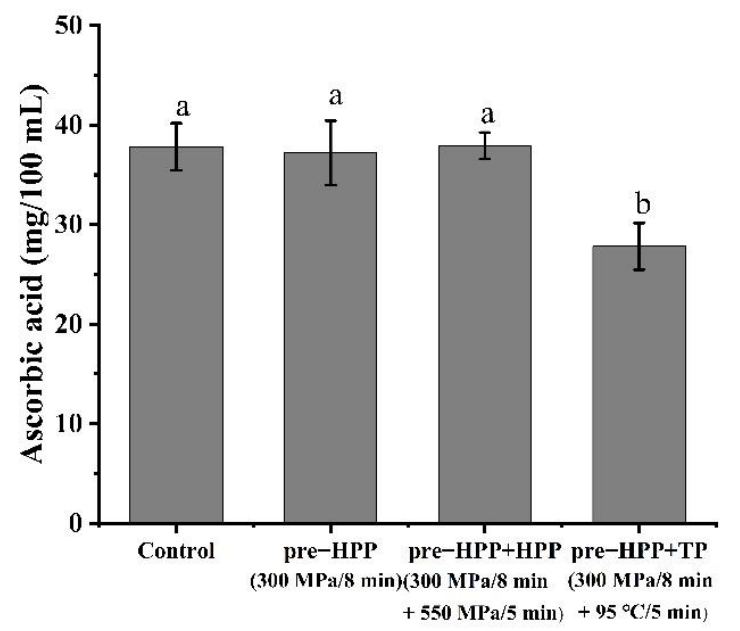

(d)

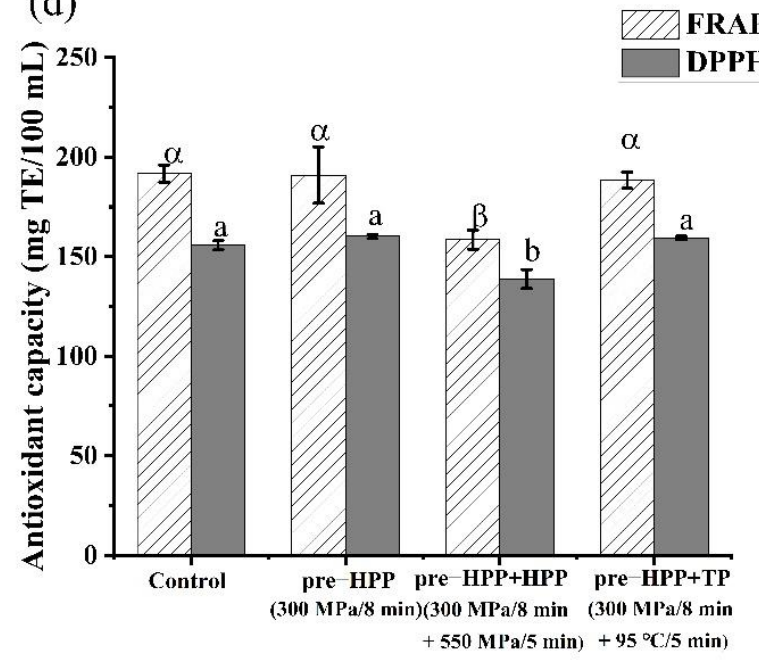

Figure 7. Effects of different treatments on (a) total phenols, (b) ascorbic acid, (c) soluble tannin, and (d) antioxidant capacity in persimmon juice. (Different letters in the same graphic indicate a significant difference $(p<0.05)$.)

Tannin is a phenolic substance, which can precipitate alkaloids, gelatin and other proteins. It has the function of antioxidation, free radical capture and bacteriostasis [36]. 
Tannin in fruit juice can protect color and improve clarity, but it can also bring some undesirable effects, such as an astringent taste, and can precipitate easily during storage of the juice. Persimmon tannin is a kind of polymer composed of catechin, catechin-3-galic acid, gallocatechin, and gallocatechin-3-galic acid. The degree of polymer polymerization directly affects the astringency intensity of persimmon. Compared with the stage of aggregation, the water-soluble tannin is the main factor that causes an astringent taste. In Figure $7 \mathrm{c}$, the soluble tannin content in the persimmon juice significantly increased by $10.84 \%$ after the pre-HPP which may have been caused by the HPP changing the permeability of the cell membrane and by more phenolic substances, such as tannin, being released. Moreover, the HPP was able to break the non-covalent bonds between the tannins and other macromolecular compounds, releasing more soluble tannins. In the samples treated by the pre-HPP plus HPP, the soluble tannin content significantly decreased by $57.28 \%$ compared to the pre-HPP treated samples, and was $38.48 \%$ lower than the thermal processing samples, indicating that a second round of HPP could decrease the astringency intensity of persimmon juice. Vázquez-Gutiérrez et al. reported that the soluble tannin content decreased significantly after HPP $\left(200 \mathrm{MPa} / 6 \mathrm{~min} / 37^{\circ} \mathrm{C}\right)$ in persimmon [37]. This phenomenon was explained by the precipitation of tannin, a result of the disruption of the cell wall and membrane with the soluble materials in the cell flowing out into the intercellular space, such as pectin and protein, which could then bind the soluble tannin [13]. The decrease in tannin content after thermal processing may be due to the decomposition of tannin at high temperature, or the formation of the tannin compound [38].

Two methods of DPPH and FRAP were used to evaluate the antioxidant capacity of the persimmon juice (Figure 7d). The changes in the antioxidant capacity of the persimmon juice were positively correlated to the content changes of total phenols, AA and soluble tannin [39]. Among the three different evaluated stages, a decrease in the antioxidant capacity was only found in the pre-HPP plus HPP treated samples, which was probably due to the second round of HPP accelerating the combination of water-soluble tannin with the protein, pectin and so forth, in order to decrease the water-soluble tannin.

\subsection{Effects of HPP and TP on the Polyphenol Oxidase Activity, Peroxidase Activity and Color of the Persimmon Juice}

The existence of polyphenol oxidase (PPO) in fruit juice is the main reason for enzymatic browning of fruit juice. The PPO can catalyze hydroxylation of free phenolic acid and dehydrogenation of hydroxy phenol to quinone in fruits and vegetables. Quinone condenses itself in fruits and vegetables or reacts with proteins in cells to produce brown pigments or melanin, which results in changes in the appearance and color of fruit juice [40]. The PPO activity increased significantly to 2.65 times of the control group after pre-HPP (300 MPa/8 min) (Figure 8a). This result is consistent with the significant increase in enzyme activity in strawberry juice treated with $300 \mathrm{MPa}$ as reported by Liu et al. [41]. This activation was hypothesized to be a result of the release of enzymes from the membrane or enzyme-inhibitor complex, or a limited conformation change. After HPP (550 MPa/5 min), the PPO activity was restored to the same level of the control group. This could be explained by the processing with a higher pressure more optimal for inactivating the PPO or by the changes induced by the pre-HPP that were reversible [42]. TP treatment significantly reduced vitality to $10.6 \%$ of the control group through destructing the enzyme structure.

Peroxidase (POD) is also related to the browning of fruit juice, and the reaction products catalyzed by POD will affect the taste and flavor of fruit juice [43]. The POD activity did not change significantly after pre-HPP (300 MPa/ $8 \mathrm{~min})$, but it was significantly activated after the HPP (550 MPa/5 min), where its activity was 1.66 times higher than that of the control group. Similar to PME, it is speculated that POD activation is related to the release of enzymes from the membrane or enzyme-inhibitor complex after HPP. Similar to PPO, TP also significantly reduced POD activity to $3.58 \%$ of the control group. 

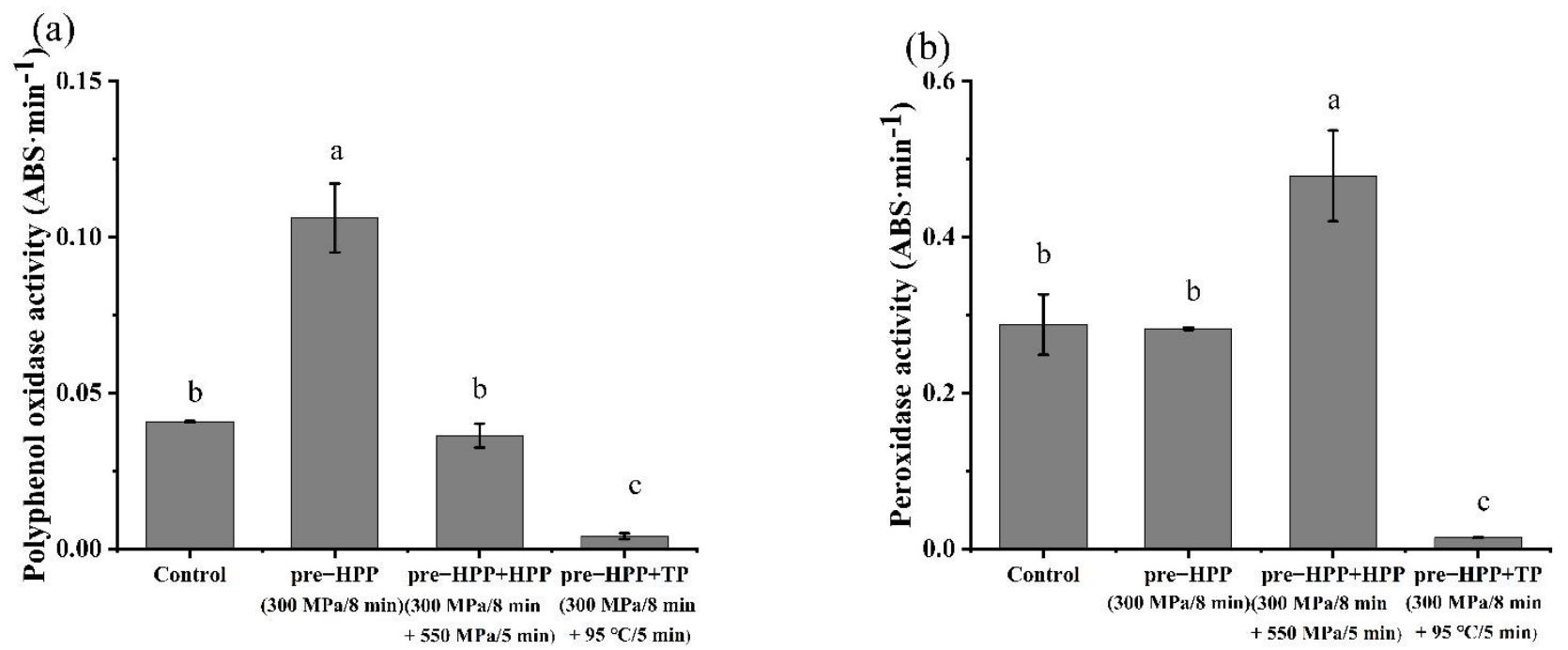

Figure 8. Effects of different treatments on (a) polyphenol oxidase activity and (b) peroxidase activity in persimmon juice. (Different letters in the same graphic indicate a significant difference $(p<0.05)$.)

According to Table 3, the pre-HPP did not induce an obvious color change in the persimmon juice with a $\Delta E$ of $0.35(\Delta E<2$, the color change is invisible to the naked eye). Additionally, the browning degree decreased significantly. The color change of the persimmon juice treated with pre-HPP plus HPP was 2.68 , slightly noticeable $(2<\Delta E<3)$, but the changes of $L^{*}, a^{*}, b^{*}$ as well as the browning degree were not significant. This might suggest that the enzymatic browning of the persimmon juice was affected by both the PPO activity and the phenolic content, especially the soluble tannin [44]. Although the pre-HPP samples had a higher PPO activity, they also contained the highest values of soluble tannin. With the pre-HPP plus TP samples, the color change was 15.38, and this was obvious ( $\Delta E>12$, can be considered as different colors), with significant changes in $L^{*}$ and $b^{*}$. The HPP treatment had less effect on color than the TP treatment. The clarity of the pre-HPP plus HPP treated samples showed no significant difference from the control group. After the pre-HPP plus TP treatment, the persimmon juice produced a large amount of white suspended matter, resulting in the clarity of the juice being reduced to less than $1 \%$. It was believed that the turbidity of the persimmon juice is caused by the combination of tannin with protein or other macromolecule substances, or by the coagulation and precipitation of colloids in the persimmon juice after thermal treatment [45].

Table 3. Effects of different treatments on color difference, BD and clarity of persimmon juice.

\begin{tabular}{|c|c|c|c|c|}
\hline Treatments & Control & Pre-HPP (300 MPa/8 Min) & $\begin{array}{c}\text { Pre-HPP + HPP (300 MPa/8 min } \\
\text { + } 550 \mathrm{MPa} / 5 \mathrm{Min})\end{array}$ & $\begin{array}{c}\text { Pre-HPP + TP (300 MPa/8 min + } \\
\left.95^{\circ} \mathrm{C} / 5 \mathrm{Min}\right)\end{array}$ \\
\hline$L^{*}$ & $35.90 \pm 0.29 b$ & $35.88 \pm 0.24 b$ & $37.39 \pm 1.91 \mathrm{~b}$ & $46.91 \pm 4.39 \mathrm{a}$ \\
\hline$a^{*}$ & $1.10 \pm 0.04 \mathrm{a}$ & $0.92 \pm 0.48 \mathrm{a}$ & $0.83 \pm 0.16 a$ & $2.18 \pm 1.66 \mathrm{a}$ \\
\hline$b^{*}$ & $4.66 \pm 0.25 b$ & $4.37 \pm 0.32 \mathrm{~b}$ & $2.45 \pm 1.16 \mathrm{~b}$ & $15.35 \pm 5.87 \mathrm{a}$ \\
\hline$\Delta E$ & 0 & 0.35 & 2.68 & 15.38 \\
\hline $\mathrm{BD}$ & $0.585 \pm 0.011 \mathrm{a}$ & $0.203 \pm 0.028 b$ & $0.189 \pm 0.022 b$ & $0.123 \pm 0.010 c$ \\
\hline Clarity (\%) & $18.2 \pm 0.3 b$ & $25.7 \pm 3.3 \mathrm{a}$ & $18.6 \pm 0.5 b$ & $0.20 \pm 0.1 \mathrm{c}$ \\
\hline
\end{tabular}

All data were the means $\pm \mathrm{SD}, n=3$. Different letters in the same row indicate a significant difference $(p<0.05)$. HPP: high pressure processing; TP: thermal processing; $\mathrm{BD}$ : browning degree.

\section{Conclusions}

"Gongcheng" was selected as the appropriate cultivar for the processing of persimmon juice, owing to its high juice yield, content of total phenols and score in the sensory evaluation. With endogenous PME activated by $25.03 \%$, the juice yield of the persimmon pulp treated with pre-HPP ( $300 \mathrm{MPa} / 8 \mathrm{~min})$ and standing at $20^{\circ} \mathrm{C}$ for $3 \mathrm{~h}$, significantly increased by $60 \%$, instead of adding an exogenous pectinase as with traditional juice 
processing technology. Both the pre-HPP plus HPP (550 MPa/5 min) and pre-HPP plus $\mathrm{TP}\left(95^{\circ} \mathrm{C} / 5 \mathrm{~min}\right)$ treatments inactivated the TAB and $\mathrm{Y} \& \mathrm{M}$ below $2 \log$ units. The color, clarity, AA and phenols were better retained after pre-HPP plus HPP and with a lower content of soluble tannin than the treatment with pre-HPP plus TP. The treatment with pre-HPP plus HPP could effectively increase the juice yield, increase the shelf life, maintain a good quality of persimmon juice and avoid re-astringency and turbidity.

Author Contributions: Conceptualization, J.X. and Y.W. (Yilun Wang); methodology, J.X., Y.W. (Yilun Wang), X.Z., Z.Z., Y.Y. and X.Y.; software, J.X. and Y.W. (Yilun Wang); validation, J.X.; formal analysis, J.X. and Y.W. (Yilun Wang); investigation, J.X., Y.W. (Yilun Wang), X.Z., Z.Z., Y.Y. and X.Y.; resources, L.Z.; data curation, J.X. and Y.W. (Yilun Wang); writing—original draft preparation, J.X. and Y.W. (Yilun Wang); writing-review and editing, J.X., Y.W. (Yilun Wang), Y.W. (Yongtao Wang), X.L. and L.Z.; supervision, L.Z.; project administration, L.Z.; funding acquisition, L.Z. All authors have read and agreed to the published version of the manuscript.

Funding: This research was funded by the National Natural Science Foundation Program of China (No. 31901707) and the 2115 Talent Development Program of China Agricultural University.

Institutional Review Board Statement: This study did not involve humans or animals.

Informed Consent Statement: This study did not involve humans.

Data Availability Statement: This study provided the data in the graphics and tables.

Acknowledgments: This work was supported by the National Natural Science Foundation Program of China (No. 31901707) and the 2115 Talent Development Program of China Agricultural University.

Conflicts of Interest: The authors declare that they have no known competing financial interests or personal relationships that could have appeared to influence the work reported in this paper.

\section{References}

1. FAO. Available online: http://www.fao.org/faostat/en/\#data/QC (accessed on 7 May 2021).

2. Anand, N.; Mukesh, K.P.; Sadhana, N. 8-Pectinases: Production and Applications for Fruit Juice Beverages. Process. Sustain. Beverages 2019, 2, 235-273.

3. Sharma, H.P.; Patel, H. Sugandha, Enzymatic added extraction and clarification of fruit juices-A review. Crit. Rev. Food Sci. Nutr. 2017, 57, 1215-1227. [CrossRef]

4. Ortuno, C.; Trang, D.; Balaban, M.; Benedito, J. Combined high hydrostatic pressure and carbon dioxide inactivation of pectin methylesterase, polyphenol oxidase and peroxidase in feijoa puree. J. Supercrit. Fluids 2013, 82, 56-62. [CrossRef]

5. Eisenmenger, M.J.; Reyes-De-Corcuera, J.I. High pressure enhancement of enzymes: A review. Enzym. Microb. Technol. 2009, 45, 331-347. [CrossRef]

6. Boulekou, S.S.; Katsaros, G.J.; Taoukis, P.S. Inactivation Kinetics of Peach Pulp Pectin Methylesterase as a Function of High Hydrostatic Pressure and Temperature Process Conditions. Food Bioprocess Technol. 2010, 3, 699-706. [CrossRef]

7. Rodriguez, A.; Cap, M.; Ramos, N.; Godoy, F.; Mascheroni, R.H.; Vaudagna, S.R. High-pressure processing of persimmon purée: Stability during chilled storage. J. Food Process. Preserv. 2020, 44, e14306. [CrossRef]

8. Kumari, A.; Farid, M. Optimization of high pressure processing for microbial load reduction in Diospyros kaki ‘Fuyu' pulp using response surface methodology. J. Food Sci. Technol. 2020, 57, 2472-2479. [CrossRef] [PubMed]

9. José Luis, V.-G.; Amparo, Q.; Erica, V.; Judith, A.J.; Isabel, H.; Nitin, N.; Diane, M.B. High hydrostatic pressure as a method to preserve fresh-cut Hachiya persimmons: A structural approach. Food Sci. Technol. Int. 2016, 22, 688-698.

10. de Ancos, B.; Gonzalez, E.; Cano, M.P. Effect of High-Pressure Treatment on the Carotenoid Composition and the Radical Scavenging Activity of Persimmon Fruit Purees. J. Agric. Food Chem. 2000, 48, 3542-3548. [CrossRef] [PubMed]

11. Lucía, P.; Clara, C.; de Ancos, B.; Concepción, S.-M.; Cano, M.P. Influence of ripening and astringency on carotenoid content of high-pressure treated persimmon fruit (Diospyros kaki L.). Food Chem. 2012, 130, 591-597.

12. Cano, M.P.; Gómez-Maqueo, A.; Welti-Chanes, J.; García-Cayuela, T. Characterization of Carotenoid and Carotenoid Esters of Astringent Persimmon Tissues (Diospyros kaki Thunb. var. Rojo Brillante). Effects of Thermal and High Pressure Non-Thermal Processing. Food Chem. 2018. [CrossRef]

13. Vázquez-Gutiérrez, J.L.; Quiles, A.; Hernando, I.; Pérez-Munuera, I. Changes in the microstructure and location of some bioactive compounds in persimmons treated by high hydrostatic pressure. Postharvest Biol. Technol. 2011, 61, 137-144. [CrossRef]

14. Hernández-Carrión, M.; Tárrega, A.; Hernando, I.; Fiszman, S.M.; Quiles, A. High hydrostatic pressure treatment provides persimmon good characteristics to formulate milk-based beverages with enhanced functionality. Food Funct. 2014, 5, 1250-1260. [CrossRef] [PubMed] 
15. Kim, Y.; Lounds-Singleton, A.J.; Talcott, S.T. Antioxidant phytochemical and quality changes associated with hot water immersion treatment of mangoes (Mangifera indica L.). Food Chem. 2009, 115, 989-993. [CrossRef]

16. Patras, A.; Brunton, N.P.; Da Pieve, S.; Butler, F. Impact of high pressure processing on total antioxidant activity, phenolic, ascorbic acid, anthocyanin content and colour of strawberry and blackberry purees. Innov. Food Sci. Emerg. Technol. 2009, 10, 308-313. [CrossRef]

17. Zhang, K. NY 82.2-1988. In Juice Determination Method-Sensory Inspection; Standards of the Ministry of Agriculture of the People's Republic of China: Beijing, China, 1988.

18. $\mathrm{Bi}, \mathrm{X} . ; \mathrm{Wu}, \mathrm{J} . ;$ Zhang, Y.; Xu, Z.; Liao, X. High pressure carbon dioxide treatment for fresh-cut carrot slices. Innov. Food Sci. Emerg. Technol. 2011, 12, 298-304. [CrossRef]

19. Amnuaysin, N.; Jones, M.L.; Seraypheap, K. Changes in activities and gene expression of enzymes associated with cell wall modification in peels of hot water treated bananas. Sci. Hortic. 2012, 142, 98-104. [CrossRef]

20. Liu, F.; Wang, Y.; Bi, X.; Guo, X.; Fu, S.; Liao, X. Comparison of Microbial Inactivation and Rheological Characteristics of Mango Pulp after High Hydrostatic Pressure Treatment and High Temperature Short Time Treatment. Food Bioprocess Technol. 2013, 6 , 2675-2684. [CrossRef]

21. Rose, J.K.C.; Hadfield, K.A.; Labavitch, J.M.; Bennett, A.B. Temporal sequence of cell wall disassembly in rapidly ripening melon fruit. Plant Physiol. 1998, 117, 345-361. [CrossRef] [PubMed]

22. Juang, L.J.; Sheu, S.J.; Lin, T.C. Determination of hydrolyzable tannins in the fruit of Terminalia chebula Retz. by high-performance liquid chromatography and capillary electrophoresis. J. Sep. Sci. 2004, 27, 718-724. [CrossRef] [PubMed]

23. Kivrak, I.; Duru, M.E.; Ozturk, M.; Mercan, N.; Harmandar, M.; Topcu, G. Antioxidant, anticholinesterase and antimicrobial constituents from the essential oil and ethanol extract of Salvia potentillifolia. Food Chem. 2009, 116, 470-479. [CrossRef]

24. Aljadi, A.M.; Kamaruddin, M.Y. Evaluation of the phenolic contents and antioxidant capacities of two Malaysian floral honeys. Food Chem. 2004, 85, 513-518. [CrossRef]

25. Zhang, Y.; Liu, X.; Wang, Y.; Zhao, F.; Sun, Z.; Liao, X. Quality comparison of carrot juices processed by high-pressure processing and high-temperature short-time processing. Innov. Food Sci. Emerg. Technol. 2016, 33, 135-144. [CrossRef]

26. Meydav, S.; Saguy, I.; Kopelman, I.J. Browning determination in citrus products. J. Agric. Food Chem. 1977, 25, 602-604. [CrossRef]

27. Rai, P.; Majumdar, G.C.; Dasgupta, S.; De, S. Optimizing pectinase usage in pretreatment of mosambi juice for clarification by response surface methodology. J. Food Eng. 2004, 64, 397-403. [CrossRef]

28. Hsu, K.-C. Evaluation of processing qualities of tomato juice induced by thermal and pressure processing. Lwt-Food Sci. Technol. 2008, 41, 450-459. [CrossRef]

29. dos Santos Aguilar, J.G.; Cristianini, M.; Sato, H.H. Modification of enzymes by use of high-pressure homogenization. Food Res. Int. 2018, 109, 120-125. [CrossRef]

30. Christiaens, S.; Van Buggenhout, S.; Houben, K.; Kermani, Z.J.; Moelants, K.R.N.; Ngouemazong, E.D.; Van Loey, A.; Hendrickx, M.E.G. Process-Structure-Function Relations of Pectin in Food. Crit. Rev. Food Sci. Nutr. 2016, 56, 1021-1042. [CrossRef] [PubMed]

31. Crelier, S.; Robert, M.C.; Claude, J.; Juillerat, M.A. Tomato (Lycopersicon esculentum) pectin methylesterase and polygalacturonase behaviors regarding heat- and pressure-induced inactivation. J. Agric. Food Chem. 2001, 49, 5566-5575. [CrossRef] [PubMed]

32. Christiaens, S.; Van Buggenhout, S.; Houben, K.; Chaula, D.; Van Loey, A.M.; Hendrickx, M.E. Unravelling process-induced pectin changes in the tomato cell wall: An integrated approach. Food Chem. 2012, 132, 1534-1543. [CrossRef]

33. Jiang, X.P.; Chen, P.; Yin, M.L.; Yang, Q. Constitutive expression, purification and characterisation of pectin methylesterase from Aspergillus niger in Pichia pastoris for potential application in the fruit juice industry. J. Sci. Food Agric. 2013, 93, 375-381. [CrossRef] [PubMed]

34. Vazquez-Gutierrez, J.L.; Hernandez-Carrion, M.; Quiles, A.; Hernando, I.; Perez-Munuera, I. Impact of high hydrostatic pressures on the structure, diffusion of soluble compounds and textural properties of persimmon 'Rojo Brillante'. Food Res. Int. 2012, 47, 218-222. [CrossRef]

35. Ribas-Agusti, A.; Van Buggenhout, S.; Palmero, P.; Hendrickx, M.; Van Loey, A. Investigating the role of pectin in carrot cell wall changes during thermal processing: A microscopic approach. Innov. Food Sci. Emerg. Technol. 2014, 24, 113-120. [CrossRef]

36. Vazquez, L.H.; Palazon, J.; Navarro-Ocana, A. The Pentacyclic Triterpenes alpha, beta-amyrins: A Review of Sources and Biological Activities. In Phytochemicals-a Global Perspective of Their Role in Nutrition and Health; Rao, V., Ed.; BoD-Books on Demand: Norderstedt, Germany, 2012; pp. 487-502.

37. Vazquez-Gutierrez, J.L.; Hernando, I.; Quiles, A. Changes in tannin solubility and microstructure of high hydrostatic pressuretreated persimmon cubes during storage at 4 A degrees C. Eur. Food Res. Technol. 2013, 237, 9-17. [CrossRef]

38. Hernandez-Carrion, M.; Vazquez-Gutierrez, J.L.; Hernando, I.; Quiles, A. Impact of High Hydrostatic Pressure and Pasteurization on the Structure and the Extractability of Bioactive Compounds of Persimmon “Rojo Brillante". J. Food Sci. 2014, 79, C32-C38. [CrossRef] [PubMed]

39. Liu, F.; Wang, Y.; Li, R.; Bi, X.; Liao, X. Effects of high hydrostatic pressure and high temperature short time on antioxidant activity, antioxidant compounds and color of mango nectars. Innov. Food Sci. Emerg. Technol. 2014, 21, 35-43. [CrossRef]

40. Fevrier, H.; Le Quere, J.M.; Le Bail, G.; Guyot, S. Polyphenol profile, PPO activity and pH variation in relation to colour changes in a series of red-fleshed apple juices. Lwt-Food Sci. Technol. 2017, 85, 353-362. [CrossRef]

41. Liu, Q.; Wang, R.F.; Zhao, X.Y.; Ma, Y.; Wang, D.; Zhang, B.B. Effect of high hydrostatic pressure processing on qualities of strawberry juice. Adv. Mater. Res. 2014, 894, 305-310. [CrossRef] 
42. Sulaiman, A.; Soo, M.J.; Yoon, M.M.L.; Farid, M.; Silva, F.V.M. Modeling the polyphenoloxidase inactivation kinetics in pear, apple and strawberry purees after High Pressure Processing. J. Food Eng. 2015, 147, 89-94. [CrossRef]

43. Serra, S.; Anthony, B.; Boscolo Sesillo, F.; Masia, A.; Musacchi, S. Determination of Post-Harvest Biochemical Composition, Enzymatic Activities, and Oxidative Browning in 14 Apple Cultivars. Foods 2021, 10, 186. [CrossRef] [PubMed]

44. Sanchis, E.; Mateos, M.; Perez-Gago, M.B. Effect of maturity stage at processing and antioxidant treatments on the physicochemical, sensory and nutritional quality of fresh-cut 'Rojo Brillante' persimmon. Postharvest Biol. Technol. 2015, 105, 34-44. [CrossRef]

45. de Freitas, V.; Mateus, N. Protein/Polyphenol Interactions: Past and Present Contributions. Mechanisms of Astringency Perception. Curr. Org. Chem. 2012, 16, 724-746. [CrossRef] 